\title{
Op-Ed
}

\section{Who pays the bill and who makes the profit in treating chronic disease?}

\author{
Lack of financial incentives means prevention is often ignored
}

John Roberts
Bellingham, WA 98226
Correspondence to:
Dr Roberts
jcroberts@hinet.org

"A courtyard common to all will be swept by none" goes a Chinese proverb. Sadly, this ancient saying remains true in the modern American medical system. At the start of the third millennium of Western culture and progress, the suffering of medical illness arguably may be higher than in the centuries past. Until the last 50 years, illness - often combined with poverty - was a greater shortener of lives. But death, compared with today, came more quickly.

In practice, an internist sees the local viewpoint of national statistics: 90 million Americans alive with chronic disease who spend more than $60 \%$ of the country's health care budget. ${ }^{1}$ Of the 20 or so patients that many physicians see each day, one, maybe two, might not have a chronic disease. Almost every one of these patients has needs far beyond what a doctor can provide. And much of the reason is inferred from two questions: "Who pays the bill?" and "Who makes the profit?"

At a policy level, the "epidemic" of chronic illness is as much a philosophical debate as it is a medical problem. If people live longer, they get illnesses of aging-dementia, loss of vision and hearing, organ failure, and cancers. In addition, chronic illness today may not have even been illness a few years ago. Mild hyperglycemia is now diabetes. The definition of hypercholesterolemia depends on at least $25 \%$ of Americans being "sufferers."

In clinical practice, philosophy is put aside in favor of what we all hope is the current best empirical evidencethat newer definitions of diabetes or elevated lipids are important in identifying people who will someday develop complications. So much of the doctor's day is spent informing patients that they have joined the ranks of the sufferers, even if they don't yet feel the suffering.

But despite the philosophy and the evolving medical evidence, nearly every doctor, at some point, feels like Alice in Wonderland when dealing with chronic diseases. Not only do the definitions change from year to year, the causes are ignored and the treatments can be trivial to the patient's well being.

Most chronic illness is a social problem. The table lists a few of the most common chronic diseases. Cardiovascular disease, cancers, chronic lung disease, and diabetes alone are responsible for about $75 \%$ of American deaths. But are these diseases solely the problem of doctor and patient? What should be the role of a doctor? Instead of prescribing nitrates and beta blockers, it may be more productive to help set up community weight-loss and activity-promoting groups. When we open our prescription pads, some of us are haunted by the question, "Could I—should I—be doing something else about this?" Too often physicians can feel they are shifting single grains of sand along the beach during a hurricane.

Except for the patient and the general community, we all do well by maintaining the status quo. Community leaders are not deposed because of their pro-health positions that would require more vigorous public health measures, and doubtless more taxes. Business firms need not spend money and energy on smoking and lifestyle modification plans for their employees, since most of the suffering will come after retirement. Hospitals and other health care institutions thrive on illness. Health plans, especially managed care plans, could plan community-wide programs to prevent chronic disease. But because of the number of plans and the frequency that customers change plans, the hopes of long-term savings from prevention strategies seem to get lost. (So now, managed care plans focus hard on a handful of measures that are used to rank the plans in a marketplace, not to prevent human suffering.)

And we doctors and our noble profession: If it pays, we do. If not, then ... well, maybe. Most of our payers reward us for meeting the prevention targets on which they are ranked-annual eye exams for persons with diabetes, beta blockers for patients who have had myocardial infarction, immunizations for children. But we perform less well when the reimbursement is not direct or is even absent. Monitoring and treating a patient with an elevated cholesterol concentration occurs less often than monitoring glycemic control. ${ }^{2}$ One can guess which is favored by payers, while the evidence might suggest we practice otherwise. $^{3}$

\begin{tabular}{|c|c|c|}
\hline Condition & $\begin{array}{l}\text { Prevalence } \\
(\%)\end{array}$ & $\begin{array}{l}\text { Annual } \\
\text { costs* }\end{array}$ \\
\hline Atherosclerotic diseases & 25 & $\$ 274$ billion \\
\hline Diabetes mellitus & 6 & $\$ 98$ billion \\
\hline Oral diseases & 86 by age 17 & \$50 billion \\
\hline Alzheimer's disease & 1.5 & $\$ 152$ billion \\
\hline \multicolumn{3}{|l|}{ Chronic obstructive } \\
\hline lung disease & 6 & $\$ 25$ billion \\
\hline Epilepsy & 1 & $\$ 14$ billion \\
\hline Osteoporosis & 4 & $\$ 15$ billion \\
\hline
\end{tabular}

From the Centers for Disease Control and Prevention, National Center for Chronic Disease Prevention and Health Promotion, Atlanta, GA

*Costs are direct and indirect and are estimates from 1993 to 1995 
Those who claim that health care is not a market might step back and take a look at the issue of chronic diseases from the community's view. At that level, for example, the cost of preventing one dental cavity through fluoridation would be $\$ 3$, while the cost of the dental repair would be $\$ 55 .^{1}$ For each of us in the medical care industry, the questions become "Whose $\$ 3$ is spent?" and "Who gets to take home the \$55?"

According to the National Center for Health Statistics, almost $20 \%$ of Americans over 45 years of age are hearing impaired, but how often do we formally assess hearing? The Center's surveys find that only about $40 \%$ of patients with diabetes have ever received formal education about controlling their diseases. In our own medical group, an informal financial analysis showed that a diabetes education program would likely be "financially negative." In chronic disease, the common good too frequently falls victim to our individual goods.

References

1 The Robert Wood Johnson Foundation, Annual Report, Princeton, NJ. 1994.

2 Ornstein SM, Jenkins RG. Quality of care for chronic illness in primary care: opportunity for improvement in process and outcome measures. Am I Manag Care 1999;5:621-627.

3 Pyorala K, Pedersen TR, Kjekshus J, et al. Cholesterol lowering with simvastatin improves prognosis of diabetic patients with coronary heart disease. A subgroup analysis of the Scandinavian Simvastatin Survival Study (4S). Diabetes Care 1997;20:614-620.

\section{Who should care for people with chronic diseases?}

\section{Members of the care team should play to their strengths and not compete for roles}

Should non-physicians care for people and families with chronic diseases? Absolutely. Chronic disease is accompanied by the need to make adjustments in lifestyle, selfimage, and the everyday life of the entire family. To expect physicians to have the expertise and time to guide patients and their families at every step of the way is unreasonable. Chronic disease care requires a team of professionals including, to name a few, a team leader; a dietitian with in-depth expertise in dietary education and rehabilitation; a physical or occupational therapist for physical accommodations and adaptations; and a family or spiritual counselor to provide support in coping with changes in the patient's or family's roles. It is possible to fall short of the team's goals if team members forget the importance of the others or if a person with a certain expertise is not easily available. But until recently, that was the most common and difficult problem.

A new problem occurs when members of a collaborative team compete for the same role. This seems to arise most often when advance practice nurses attempt to claim the role of medical team leader. The concept of the nurse practitioner or advanced practice nurse is not new. In the 1970s, nurses began to develop special training programs to prepare for nursing in unique situations: rural areas, neonatal intensive care units, and operating rooms. ${ }^{1,2}$ The nurses selected to receive further training had many years of experience. Reports of nurses in these roles stated that they worked collaboratively with physicians, often providing services in narrow areas such as general anesthesia in low risk operative procedures, the routine care of high risk newborns in specialized units, or assessment and treatment of minor illnesses with frequent consultation and constant availability of physicians.

Many reports describe nurses doing similar work in special programs for a single chronic disease, such as asthma, rheumatoid arthritis, myocardial infarction, or stroke. Most of these programs are under the umbrella of a tertiary care hospital system that provides regular evaluation of the patients and required medical services. ${ }^{3-5}$ Few of these programs have been adequately evaluated to determine the long-term outcomes and patient satisfaction with their care for that specific disease.

While these special care programs led by nurses may meet the needs of the small group of people with chronic diseases who receive care at tertiary centers, they are not as feasible for people receiving care in a general practice setting. In most such settings, it is not a single chronic disease, but a multitude of conditions, that requires the team approach.

Should nurses become the medical team leaders or primary care givers for all of these many conditions? Not only is this concept inconsistent with the focus and duration of their training, ${ }^{6-8}$ but also, who will provide the advanced nursing care and expertise that have served patients so well?

We have a model of the effective use of the unique skills of nurses to assess and monitor the progress of patients and their families. That model comes from the hos-
Barbara P Yawn

Olmstead Medical

Center

Rochester, MN 55904

Correspondence to: Dr Yawn

Yawn002@gold.tc.umn. edu 
pital. No one (except administrators who are focused on cost) believes that the hospital could function without the primary role of the nurse as a nurse and a collaborating member of the health care team. Hospital nurses don't strive to become team leaders; they recognize there is a unique role for nurses applying their nursing skills.

Can such a team work in the ambulatory care setting? I believe so, having practiced as a member of that team. People and families who live with chronic diseases need individualized medical care programs, dietary programs, physical therapy programs and nursing programs. Nurses are uniquely equipped to provide practical education on the everyday activities of people with chronic diseases..$^{9-11}$ They know how to provide a detailed nursing assessment of patients and their families, without which many patients and families do not receive maximum benefit from the medical regimens designed for them. The medical regimen may fail to account for financial stress, cultural dissonance or a knowledge gap that a nursing assessment may identify. Follow-up visits to the nurse, or better yet home visits, will of course include the physical diagnostic skills of the advanced practice nurse. ${ }^{12,13}$

But the education will not stop with the patient and family. The nurse can teach the other members of the team how to identify many barriers to and enhancements of caring for the family. We should collaborate using the strengths of advanced nursing skills to ensure not only satisfaction with our professional roles, but the best care for the people and families living with chronic diseases.

References

1 Levine DM, Morlock LL, Mushlin AI, et al. The role of new health practitioners in a prepaid group practice: provider differences in process and outcomes of medical care. Med Care 1976;14:326-347.

2 Yodfat Y, Fidel J, Eliakim M. Analysis of the work of nurse-practitioners in family practice and its effect on the physicians activities. J Fam Pract 1977;4:345-350.

3 Ketelaars CA, Huyer Abu-Saad H, Halfens RJ, et al. Effects of specialized community nursing care in patients with chronic obstructive pulmonary disease. Heart Lung 1998;27:109-120.

4 Smith LD. Continuity of care through nursing case management of the chronically ill child. Clin Nurse Spec 1994;8:65-68.

5 Urbano MT, vonWindeguth B, Siderits P, et al. Developing case managers for chronically ill children: Florida's registered nurse specialist program. J Contin Educ Nurs 1991;22:62-66.

6 Mesters I, Meertens R, Mosterd N. Multidisciplinary co-operation in primary care for asthmatic children. Soc Sci Med 1991;32:65-70.

7 Robertson R, Osman LM, Douglas JG. Adult asthma review in general practice: nurses' perception of their role. Fam Pract 1997;14:227-232.

8 Nolan M, Nolan J. Rehabilitation, chronic illness and disability: t he missing elements in nurse education. J Adv Nurs 1999;29:958966.

9 Connelly SV, Connelly PA. Physicians' patient referrals to a nurse practitioner in a primary care medical clinic. Am J Public Health 1979;69:73-75

10 Lamm B, Dungan JM, Hiromoto B. Long-term lifestyle management. Clin Nurse Spec 1991;5:182-188.

11 Steen J. Liaison nurse: ombudsman for the chronically ill. Am J Nurs 1973;73:2102-2104.

12 Aguilar N. Counseling the patient with chronic illness: strategies for the health care provider. J Am Acad Nurse Pract 1997;9:171-175.

13 Martin SD. Coping with chronic illness. Home Health Nurse 1995; 13:50-54.

\section{The epidemic of obesity}

\section{A chronic disease that governments worldwide must take seriously}

George A Bray
Pennington Biomedical
Research Center
6400 Perkins Rd
Baton Rouge, LA 70808
Jennie Macdiarmid
International Obesity
Task Force
Rowett Institute
Aberdeen, Scotland
Correspondence to:
Dr Bray
brayga@prbc.edu
Competing interests:
Both authors are
members of the
International Obesity
Task Force of the
Obesity Management
Practices Working
Group

The worldwide epidemic of obesity is reaching critical proportions..$^{1-3}$ An estimated 250 million people in the world are obese, and this number is predicted to reach 300 million by $2025 .{ }^{1}$ Obesity is a chronic disease that is caused by eating more calories than are expended. Obese people are, therefore, stigmatized. Obesity causes pathologic changes in the body: enlarged or hypertrophic fat cells produce associated clinical complications such as diabetes mellitus, gallbladder disease, hypertension, and some forms of cancer by releasing more free fatty acids, cytokines, and other products of fat cell metabolism

As a major risk factor for a number of noncommunicable diseases, including diabetes mellitus, coronary heart disease, hypertension, osteoarthritis, gallbladder disease, and some forms of cancer, obesity merits a high priority for strategies for prevention and, where this fails, for clini$\mathrm{cal}$ management. The increasing prevalence of obesity will have a major effect on health care costs. ${ }^{4}$ In addition to the direct costs, there are many indirect economic and social costs that are often forgotten. Obesity has joined the ranks of chronic diseases that have displaced undernutrition and infectious diseases as the major killers of people. ${ }^{5}$

Preventive strategies are the primary tools to slow or reverse the worldwide explosion of obesity. ${ }^{1}$ This is where governmental research and demonstration projects are urgently needed. No matter how effective preventive strategies may be, however, there will still be a large pool of people who are already at risk of complications from their obesity and who need treatment. Viewing obesity as a multifactorial disease with distinctive pathologic and pathophysiologic processes provides a medical framework in which to consider treatment. A major difference exists between obesity and other chronic diseases such as hypertension or atherosclerosis. The presence of obesity is evident to obese people as well as to casual observers- that of hypertension and atherosclerosis is not. Thus, the management strategies for treatment and secondary prevention of weight regain must be appropriate and safe enough for 
use by all overweight people, even those who may be without clear medical indications for intensive interventions such as drug treatment. ${ }^{6}$

The problem of managing obesity needs to be tackled immediately. Although health care services for obesity exist in many countries, these tend to be located in cities (often in specialist hospitals), where people often have to pay for their treatment. This limits the service to the more affluent, depriving those in rural areas and people of lower socioeconomic status or those belonging to ethnic minorities of these services. Yet, people in lower socioeconomic groups have a high incidence of obesity. ${ }^{7}$ This group needs to be targeted for treatment but is being excluded by the health care system. In some countries, health insurance companies pay for the treatment of obesity, but most insurance carriers in North America do not. Funding is a major consideration in the management of all chronic diseases, but this is complicated further in patients with obesity, a disease that is still not recognized as such in many countries. ${ }^{7}$ This is an area that urgently needs public and governmental action.

An international obesity management strategy could provide a framework on which to base national guidelines for the management of obesity. Many political, attitudinal, cultural, and geographic factors need to be taken into consideration when implementing guidelines. Many government and health systems have a negative attitude to obesity, which highlights the need to raise awareness of obesity as a serious health condition. ${ }^{5}$
A multinational campaign for people to "Know your body mass index" could be a first step in raising public and professional awareness of this global epidemic. When the ravages of hypertension and atherosclerosis were recognized, governmental programs were aimed at encouraging the public to "Know your blood pressure" and "Know your cholesterol" and to seek treatment when needed.

Although many countries are starting to recognize the problem and to take it seriously, much still needs to be done to prevent and manage obesity effectively. The vital link between the lack of funding and lower socioeconomic status will need special consideration in all strategies to manage obesity.

References

1 World Health Organization. Obesity: preventing and managing the global epidemic. Geneva (Switzerland): World Health Organization; 1977.

2 Clinical guidelines on the identification, evaluation, and treatment of overweight and obesity in adults. Bethesda (MD): National Heart, Lung and Blood Institute, US Dept of Health and Human Services; 1998.

3 Mokdad AH, Serdula MK, Dietz WH, et al. The spread of the obesity epidemic in the United States, 1991-1998. JAMA 1999;282:1519-1522.

4 Bray GA. Obesity: a time bomb to be defused. Lancet 1998;352:160-161.

5 Allison DB, Fontaine KR, Manson JE, et al. Annual deaths attributable to obesity in the United States. JAMA 1999;282:1530-1538.

6 Bray GA. Drug treatment of obesity: don't throw out the baby with the bath water. Am J Clin Nutr 1998;67:1-2.

7 Bray GA, Macdiarmid JI. Obesity: a global risk factor for disease? In: Guy-Grand B, Ailhaud G, eds. Progress in obesity research. London (England): Libbey and Company, 1999.

\section{BIBA but LGFTD}

The purist element in most of us dislikes the use of abbreviations. We tend to view them as unsightly, a blot on the language, a sign of laziness or ignorance. We are irritated that only a select few (but others than ourselves) understand what they mean.

Take AB, a 59yo BM (a non-scatological term) S/P TURP/DES, BBPR, with elevated JVD from CHF, Dx GOK or NYD. Or William Bean's patient (Tower of Babel, 1963), a “45 yo SCF hsewfe G10 P6A4 c C.C SOB, 4mo PTA. Sn's \& Sx’s CHF c PND, DOE, \& PE. LMD found m's of MS, MI, AS, AI \& ?IVSD (R/O IASD \& PDA). EKG showed LVH, RVH, LAH, RBB, PVC's, AF, old MI ....” Despite further w/o and Rx, "on the second day the patient jumped out of the window."

Nowadays, computer literate residents prefer to write case insensitive histories, such as “49 hisp, fem, hd, sz, htn, sob, cp, ccu, dx esrd, $\mathrm{dm}$, ams, cp, chf, gi obstr." Some medical journals allow so many abbreviations that their articles cannot be read without constant reference to a glossary.

Yet long words take a long time to write down, and people have always felt the need to use abbreviations. In the 19th century, in her letters, Jane Austen referred to her novels as P\&P, S\&S, and MP. A popular system used lower caps superscripts, such as inform ${ }^{n}$, commun ${ }^{n}$, or realisa". A recent computer search disclosed 14,994 matches for "medical abbreviations"-lists, glossaries, dictionaries, and even books. Hospital committees periodically publish lists of "approved" abbreviations_-largely ignored.

How much more practical are the stock exchanges, where symbols for MCD (what we eat), BUD (what we drink), MO (what we smoke), or MRK and GLX (drug makers) are official, fixed, and universally recognizable? It is a pity that medicine does not have such a universally agreed system, at least for some commonly used terms. It would eliminate a great deal of confusion and errors, as well as much hd, aggr, and wc (writer's cramp).

(Glossary for the uninitiated: BIBA, brought in by ambulance; LGFTD, looks good from the door; BBPR, bright blood per rectum; SP/TUR, status post-transurethral resection of prostate; GOK, God only knows; NYD, not yet diagnosed; hd, headache; sz, seizures; cp, chest pain; ccu, coronary care unit; dm, diabetes mellitus.)

George Dunea, Cook County Hospital, Chicago, IL 